\title{
FOXO3a and the MAPK p38 are activated by cetuximab to induce cell death and inhibit cell proliferation and their expression predicts cetuximab efficacy in colorectal cancer
}

L Marzi 1,2,3,4,7, E Combes ${ }^{1,2,3,4,7}$, N Vié1,2,3,4 , A Ayrolles-Torro ${ }^{1,2,3,4}$, D Tosi ${ }^{1,2,3,4}$, D Desigaud ${ }^{1,2,3,4}$, E Perez-Gracia 1,2,3,4, C Larbouret ${ }^{1,2,3,4}, C$ Montagut ${ }^{5}$, M Iglesias $^{5}, M$ Jarlier ${ }^{1,2,3,4}$, V Denis ${ }^{1,2,3,4}$, L K Linares ${ }^{1,2,3,4}$, EW-F Lam ${ }^{6}$, P Martineau ${ }^{1,2,3,4}$, M Del Rio ${ }^{1,2,3,4}$ and C Gongora ${ }^{\star 1,1,2,3,4}$

${ }^{1}$ IRCM, Institut de Recherche en Cancérologie de Montpellier, Montpellier, F-34298, France; ${ }^{2}$ INSERM, U1194, Montpellier F-34298, France; ${ }^{3}$ Université Montpellier, Montpellier F-34298, France; ${ }^{4}$ Institut régional du Cancer Montpellier, Montpellier F-34298, France; ${ }^{5}$ Department of Medical Oncology, Hospital del Mar, Barcelona 08003, Spain and ${ }^{6}$ Department of Surgery and Cancer, Imperial Centre for Translational and Experimental Medicine (ICTEM), Imperial College London, Hammersmith Hospital Campus, London W12 ONN, UK

Background: Cetuximab, a monoclonal antibody against EGFR used for the treatment of colorectal cancer (CRC), is ineffective in many patients. The aim of this study was to identify the signalling pathways activated by cetuximab in CRC cells and define new biomarker of response.

Methods: We used in vitro, in vivo models and clinical CRC samples to assess the role of p38 and FOXO3a in cetuximab mechanism of action.

Results: We show that cetuximab activates the MAPK p38. Specifically, p38 inhibition reduced cetuximab efficacy on cell growth and cell death. At the molecular level, cetuximab activates the transcription factor FOXO3a and promotes its nuclear translocation via p38-mediated phosphorylation, leading to the upregulation of its target genes p27 and BIM and the subsequent induction of apoptosis and inhibition of cell proliferation. Finally, we found that high FOXO3a and p38 expression levels are associated with better response rate and improved outcome in cetuximab-treated patients with CRC harbouring WT KRAS.

Conclusions: We identify FOXO3a as a key mediator of cetuximab mechanism of action in CRC cells and define $\mathrm{p} 38$ as its activator in this context. Moreover, high FOXO3a and p38 expression could predict the response to cetuximab in patients with CRC harbouring WT KRAS.

Colorectal cancer (CRC) is the fourth most common cancer worldwide. In 2012, the estimated CRC incidence was of 1.3 million cases worldwide and CRC caused $>700000$ deaths (Ferlay et al, 2010). CRC is classified into four stages from the TNM classification data. The cure for CRC depends on the stage at which it is detected. The first treatment is the surgical resection which removes the colonic segment with the tumour and the surrounding lymph nodes, which can be carriers of micrometastases. This surgery is accompanied by chemotherapy for stage III and IV or radiochemotherapy for advanced rectal cancers. In all, $30 \%$ of

\footnotetext{
${ }^{*}$ Correspondence: Dr C Gongora; E-mail: celine.gongora@inserm.fr

${ }^{7}$ These authors contributed equally to this work.
}

Revised 8 July 2016; accepted 6 September 2016; published online 29 September 2016

(c) 2016 Cancer Research UK. All rights reserved 0007-0920/16 
patients present synchronous metastases and 50-60\% will develop metastases that will require chemotherapy. The current management is based on various drugs (5-FU/LV, capecitabine, irinotecan, oxaliplatin, bevacizumab, cetuximab and panitumumab) either in combination or as single agents (Van Cutsem et al, 2010). Thanks to these treatments, the patients' overall survival has been significantly improved, but tumour resistance is still a frequent cause of therapy failure.

Among the drugs used in CRC treatment, cetuximab is a monoclonal antibody that targets the extracellular domain of epithelial growth factor receptor (EGFR) and can overcome acquired resistance to irinotecan chemotherapy (Cunningham et al, 2004). However, patients with KRAS-mutated metastatic CRC (mCRC) do not benefit from this treatment (Amado et al, 2008; Karapetis et al, 2008) and 40-60\% of patients with wild-type KRAS mCRC do not respond to cetuximab. Cetuximab binding to EGFR inhibits receptor activation and, subsequently, signal transduction of the RAS/RAF/MEK/ERK and the PI3K/AKT pathways (Okada et al, 2014). This leads to cell cycle arrest and/or induction of apoptosis. The downstream cellular targets of cetuximab are not fully characterised and most of the transcription factors induced by cetuximab have not been identified.

The serine/threonine MAPK p38 (Zarubin and Han, 2005) is activated through phosphorylation at the $\mathrm{Thr}^{180}$-Gly-Tyr ${ }^{182}$ motif by MKK3, MKK4 and MKK6 (Wilson et al, 1996). Phosphorylated p38 activates a wide range of substrates, leading to diverse responses, such as cell differentiation, cell cycle arrest, apoptosis, senescence, cytokine production, regulation of RNA splicing and inflammatory responses (Cuenda and Rousseau, 2007). We previously showed that p38 is activated by treatment with SN38 (the active metabolite of irinotecan) and that pharmacological inhibition of p38 overcomes irinotecan and SN38 resistance (Paillas et al, 2011). Recently, Ho et al (2012) showed that p38 can phosphorylate the transcription factor FOXO3a and contributes to its nuclear localisation and activation. FOXO3a biological activity is mainly modulated via inhibitory phosphorylation by the PI3K/AKT and MEK/ERK pathways (Biggs et al, 1999; Yang et al, 2008; van der Vos and Coffer, 2011). Conversely, inhibition of AKT and ERK can lead to de-phosphorylation, nuclear localisation of FOXO3a and to its activation. This activation induces cell cycle arrest and/or apoptosis through upregulation of its target genes, such as $p 27^{K i p 1}$ (CDKN1B) and BIM (van der Vos and Coffer, 2011).

In the present study, we investigated the molecular pathways induced by cetuximab and involved in cetuximab-mediated cell proliferation inhibition and apoptosis induction. Particularly, we explored the role of $\mathrm{p} 38$ in FOXO3a regulation in response to cetuximab in wild-type KRAS CRC cells. Finally, we studied FOXO3a and p38 expression levels in CRC samples and correlated them with the patients' response to cetuximab treatment.

\section{MATERIALS AND METHODS}

Reagents. Cetuximab (Erbitux) was purchased from Merck (Darmstadt, Germany). SB202190 and SP600125 were purchased from Sigma-Aldrich (St. Louis, MO, USA). Lapatinib (Tyverb) and erlotinib (Tarceva) were purchased from ICM (Montpellier, France). Primary antibodies against phospho-p38, phospho-AKT, phosphoERK, phospho-JNK, phospho-ATF2, p38 $\alpha$, cleaved-caspase 3, tubulin, FOXO3a, BIM and p27 were purchased from Cell Signaling Technology (Danvers, MA, USA); the anti-FOXO3a-phosphoSer7 antibody was obtained from EW-F Lam (Ho et al, 2012). Secondary antibodies were horseradish peroxidase-conjugated anti-mouse or anti-rabbit antisera (Sigma-Aldrich).
Kinase assay. The p38 kinase assay was performed using the nonradioactive p38 MAPK Assay Kit from Cell Signaling Technology, as previously described (Gongora et al, 2008).

Cell culture and retroviral infections. The human EGFR-overexpressed, WT KRAS, rectum adenocarcinoma DiFi cell line was obtained from Dr Clara Montagut (Montagut et al, 2012; Siravegna et al, 2015). Cells were grown in DMEM supplemented with $10 \%$ fetal calf serum and $2 \mathrm{mM} \mathrm{L}$-glutamine at $37^{\circ} \mathrm{C}$ in humidified atmosphere with 5\% CO2. DiFi cells expressing ShRNAs targeting luciferase, $p 38 \alpha, F O X O 3 a, B I M$ and $p 27$ were obtained by retroviral gene transduction of the pSIREN vector in which the ShRNAs were cloned. Cells were selected with $1 \mu \mathrm{g} \mathrm{ml}^{-1}$ puromycin and then stable clones were pooled.

Plasmids. The pCMV-FLAG-tagged human wild-type FOXO3a and mutated FOXO3a S7A expression vectors have been previously described (Ho et al, 2012).

Subcellular protein extraction and immunoprecipitation. In all, $3 \times 10^{6} \mathrm{DiFi}$ cells were scraped, lysed and centrifuged at 3500 r.p.m. Supernatants containing cytosolic proteins were stored. Pellets were then lysed in $3 \mathrm{~mm}$ EDTA, $0.2 \mathrm{~mm}$ EGTA and protease inhibitors, and then vortexed to obtain the nuclear protein fraction. Immunoprecipitations were performed using $0.4 \mathrm{mg}$ of proteins, protein A/G magnetic beads (Pierce, Waltham, MA, USA) and the anti-FOXO3a antibody (Cell Signaling Technology).

Immunofluorescence. Cells were plated on $12 \mathrm{~mm}$ glass coverslips in culture dishes. They were fixed in 3.7\% formaldehyde, blocked in PBS with $1 \%$ BSA and $0.3 \%$ Triton and incubated with an anti-FLAG monoclonal antibody Sigma-Aldrich and then with an anti-mouse Alexa Fluor 488 (Invitrogen, Life Technologies, Carlsbad, CA, USA). DAPI was used to stain nuclei. Coverslips were then mounted in Moviol and images were recorded using a 63XNA objective and a Leica inverted microscope (Wetzlar, Germany).

RNA preparation and RT-qPCR. Total RNA was isolated from DiFi cells using the RNeasy mini Kit (Qiagen, Hilden, Germany) with a DNAse digestion step. Total RNA ( $1 \mu \mathrm{g})$ was reversetranscribed using the SuperScript III reverse transcriptase (Invitrogen, Life Technologies). Real-time quantitative PCR (qPCR) was performed using the LC480 cycler (Roche Diagnostics, Meylan, France) according to the manufacturer's instruction. The amplification specificity was verified by melting curve analysis. Real-time PCR values were determined by reference to a standard curve that was generated by real-time PCR amplification of a serially diluted cDNA sample using primers specific for $p 27, B I M$ and $28 s$. The quantification data were normalised to the amplification data for the reference gene $28 \mathrm{~s}$.

Drug sensitivity assay. Cell growth inhibition and cell viability after cetuximab incubation were assessed using the sulforhodamine B (SRB) assay, as previously described (Candeil et al, 2004; Paillas et al, 2011).

Cell death analysis. Cell death analysis was performed using the Annexin V-FITC/7-AAD Kit (Beckman Coulter, Indianapolis, IN, USA). Cells were incubated with $0.5 \mu \mathrm{g} \mathrm{ml}^{-1}$ cetuximab, $5 \mu \mathrm{M}$ SB202190, or $0.5 \mu \mathrm{g} \mathrm{ml}^{-1}$ cetuximab $+5 \mu \mathrm{M} \mathrm{SB} 202190$ for $48 \mathrm{~h}$. Cells $\left(1 \times 10^{6}\right)$ and the corresponding supernatants were labelled using the Annexin V-FITC/7-AAD Kit (Beckman Coulter, Indianapolis, IN, USA). Analyses were done on a FC500 Beckman Coulter Flow Cytometer (Beckman Coulter). Annexin V-FITC positive cells were quantified using the Flow Jo analysis software (Treestar, Ashland, OR, USA).

Cell cycle analysis. Cells were treated with $0.5 \mu \mathrm{g} \mathrm{ml}^{-1}$ cetuximab, $5 \mu \mathrm{M} \mathrm{SB} 202190$, or $0.5 \mu \mathrm{g} \mathrm{ml}^{-1}$ cetuximab $+5 \mu \mathrm{M}$ SB202190 for $48 \mathrm{~h}$. In all, $1 \times 10^{6}$ cells were pelleted, washed with PBS, fixed in $75 \%$ ethanol, treated with $100 \mu \mathrm{g} \mathrm{ml}^{-1}$ RNAse (Qiagen) and stained with $40 \mu \mathrm{g} \mathrm{ml}^{-1}$ propidium iodide. The cell cycle 
distribution was determined with a FC500 Beckman Coulter Flow Cytometer using the FL-3 channel. Cells were gated on a dot plot that displayed the DNA-pulse-peak $v s$ the DNA-pulse area to exclude doublets. Cell cycle distributions were illustrated using the Flow Jo analysis software (Treestar, FLOWJO, Ashland, OR, USA).

Cell proliferation analysis. Cell proliferation was measured by incorporating 5-ethynyl-2'-deoxyuridine (EdU) into DNA during the active DNA synthesis (i.e., the last $30 \mathrm{~h}$ of culture). After cell fixation-permeabilization in $75 \%$ ethanol/PBS-incorporated Edu was labelled and detected with the Click-iT EdU Alexa Fluor 488 Flow Cytometry Assay Kit (Invitrogen). Analyses were done on a FC500 Beckman Coulter Flow Cytometer. Alexa Fluor 488conjugated EdU-positive cells were quantified using the Flow Jo analysis software (Treestar).

\section{In vivo studies}

Xenografts. Female athymic $n u / n u$ mice were purchased from Harlan Laboratories (Gannat, France) and used when 6-8-weekold. A total of, $2 \times 10^{6}$ Difi or Caco 2 tumour cells in Matrigel were injected subcutaneously (s.c.) into the left flank of each mouse. Tumours were detected by palpation and measured with calipers weekly (or every 10 days). Mice were killed when the tumour volume reached $1000 \mathrm{~mm}^{3}$. We obtained ethical approvals for these experiments (ethics committee approved by the French Ministry, animal facility approval C34-172-27, personal approval (Céline Gongora) 34.142 and protocol approval CEEA-LR-12104).

Cetuximab and SB202190 treatment. When tumours reached the volume of $100 \mathrm{~mm}^{3}$, mice were treated with: (i) $5 \mathrm{mg} \mathrm{kg}^{-1}$ cetuximab by intraperitoneal (i.p.) injection twice per week for 4 weeks; (ii) $0.2 \mathrm{ml}$ of $0.9 \%$ sodium chloride solution (control group) by i.p. injection twice per week for 4 weeks; (iii) $0.05 \mu \mathrm{mol} \mathrm{kg}^{-1}$ SB202190 (stock solution diluted in $0.9 \%$ sodium chloride) by i.p. injection five times per week for 4 weeks; or (iv) cetuximab + SB202190: $5 \mathrm{mg} \mathrm{kg}^{-1}$ cetuximab twice per week $+0.05 \mu \mathrm{mol} \mathrm{kg}^{-1}$ SB202190 five times per week, both for 4 weeks.

Statistical analysis. A linear mixed-regression model, containing both fixed and random effects, was used to determine the relationship between tumour growth and number of days after grafting. BLI data were first transformed using the natural log scale to better fit the assumptions of the linear mixed model. The fixed part of the model included variables corresponding to the number of post-graft days and the different treatments. Interaction terms were built into the model; random intercepts and random slopes were included to take time into account. The coefficients of the model were estimated by maximum likelihood and considered significant at the 0.05 level. Statistical analysis was performed using the STATA 10.0 software (Stata Corp., College Station, TX, USA).

Clinical samples. We have recovered from public database transcriptome data of the cetuximab-treated patient's cohort of Khambata-Ford data set, (GSE5851; Khambata-Ford et al, 2007) that includes gene-expression data from 80 patients with mCRC enroled for treatment with cetuximab monotherapy. Authors indicate that written informed consent was obtained from all patients before they entered the study. The protocol was approved by the institutional review boards at the participating institutions. On the basis of the assessment of the best clinical response, patients with mCRC harbouring WT KRAS $(n=43)$ could be classified as responders (partial response, $n=5$; and stable disease, $n=15$; total $=20$ ) and non-responders (progressive disease, $n=19$ ). The response in 4 of these 43 patients could not be determined. KRAS status was assessed in 69 patients (WT KRAS $=42$ and mutated KRAS $=27$.

\section{RESULTS}

The MAPK p38 is activated by cetuximab. Cetuximab inhibits EGFR activation and subsequently signal transduction of the RAS/ RAF/MEK/ERK and PI3K/AKT pathways. However, its impact on other major cell signalling pathways is not clear. Here, we analysed cetuximab effect on the two stress kinases JNK and p38. To this aim, we used the Difi colon cancer cell line that is characterised by high-level EGFR amplification, WT KRAS and BRAF and is highly sensitive to cetuximab. Indeed, exposure to very low cetuximab concentrations leads to growth arrest and apoptosis ( $\mathrm{Lu}$ et al, 2007a, b; Montagut et al, 2012; Kawakami et al, 2014). Western blot analysis using anti-p38 and -JNK phospho-specific antibodies showed an increase of p38 and JNK phosphorylation in the DiFi human CRC cell line following incubation with $10 \mu \mathrm{g} \mathrm{ml}^{-1}$ of cetuximab for $24 \mathrm{~h}$ (Figure 1A). As expected, AKT and ERK phosphorylation were strongly decreased in cetuximab-treated DiFi cells, indicating that DiFi cells respond accurately to this antiEGFR treatment.

We then analysed whether JNK and p38 activation had a functional impact on cetuximab effect on cell death and proliferation. To this aim, we inhibited JNK or p38 with specific inhibitors (SP600125 for JNK and SB202190 for p38) and then tested cetuximab cytotoxicity using the SRB assay (Figure 1B). Cetuximab cytotoxicity was not affected by JNK inhibition, but was greatly reduced following p38 inhibition, as indicated by the higher $\mathrm{IC}_{50}$ of cetuximab $\left(55 \mathrm{ng} \mathrm{ml}^{-1}\right.$ ) when associated with SB202190 compared with when used alone $\left(35 \mathrm{ng} \mathrm{ml}^{-1} ; P\right.$-value: 0.005$)$. This indicates that inhibition of p38 makes DiFi cells more resistant to cetuximab.

We then measured phosphorylation of the p38 target protein ATF2 by kinase assay to evaluate the effect of cetuximab and SB202190 on p38 activity (Figure 1C, upper panel). ATF2 phosphorylation was increased in cetuximab-treated $\mathrm{DiFi}$ cells and this effect was lost when cetuximab was combined with SB202190. Immunoblot analysis using a phospho-specific anti-p38 antibody confirmed cetuximab effect on p38 basal activity (Figure 1C, lower panel). We then investigated whether inhibition of p38 activity by SB202190 could affect also cetuximab-mediated ERK and AKT inhibition (Figure 1D). SB202190 alone reduced only slightly AKT phosphorylation, but strongly inhibited AKT phosphorylation when in combination with cetuximab. Conversely, SB202190 increased ERK phosphorylation when used alone, and reduced cetuximab-mediated inhibition of ERK phosphorylation when associated with the antibody.

These data suggest that the MAPK p38 is activated by cetuximab and contributes to its cytotoxic effect.

The MAPK p38 is necessary for the cytotoxic effect of EGFRtargeting compounds. We then investigated the effect of p38 activity inhibition on cetuximab sensitivity in mice injected s.c. with Difi cells. When tumours reached $100 \mathrm{~mm}^{3}$, xenografted mice were divided in four groups: one group was left untreated, one was treated with cetuximab alone, one with SB202190 alone, and the last group with cetuximab and SB202190 (Figure 1E). Cetuximab was the most effective treatment compared with no treatment $(P<0.001)$ or SB202190 alone $(P<0.001)$, which had only a minor effect on tumour growth. The combination of cetuximab and SB202190 also was less effective than cetuximab alone $(P=0.022)$. This result confirms the previous observation obtained in vitro (Figure 1B) and provides evidence that inhibition of p38 activity can partially inhibit sensitivity to cetuximab in vivo.

We then tested in vitro, whether p38 silencing could affect cetuximab cytotoxic activity in the same way as the p38 inhibitor SB202190. By using the SRB assay we showed that sensitivity to cetuximab was reduced in $\mathrm{DiFi}$ cells in which p38 was 

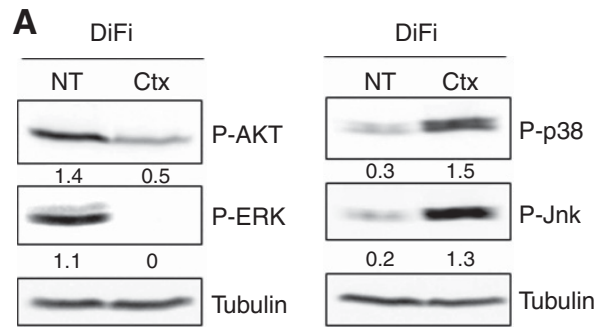

C

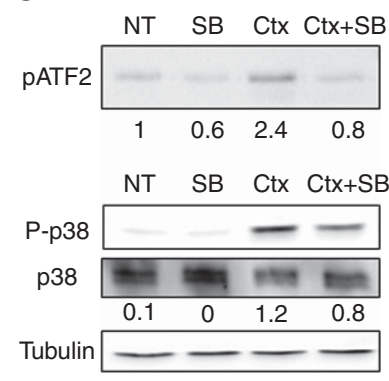

D

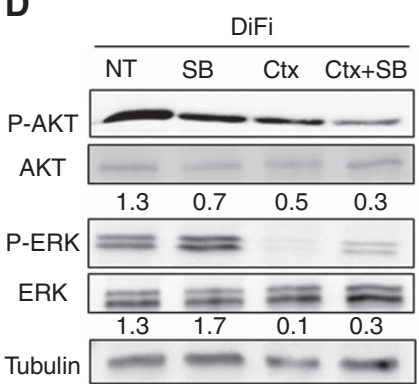

B
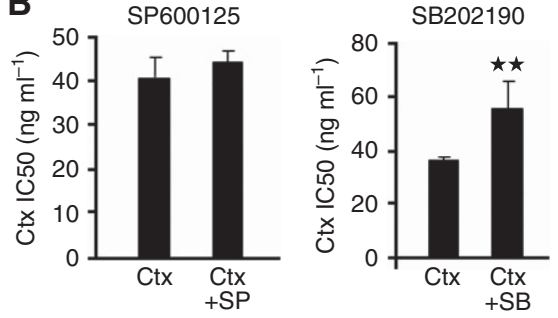

E

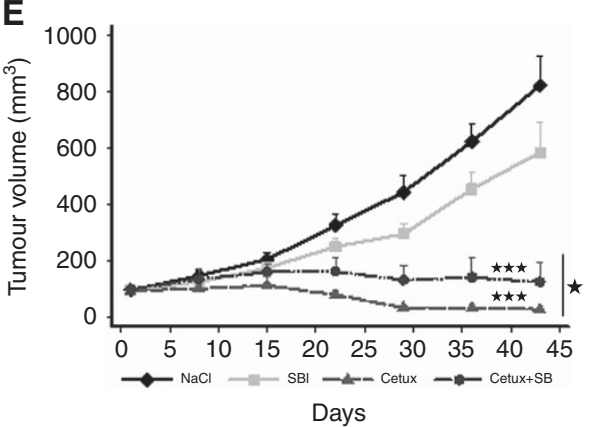

Figure 1. The MAPK p38 is activated by cetuximab. (A) Western blot analysis of phospho-AKT (P-AKT), phospho-ERK (P-ERK), phospho-p38 (Pp38) and phospho-JNK (P-JNK) in DiFi cells incubated with cetuximab (Ctx) for 24 h. Equal loading is shown by tubulin (Tub). (B) SRB assays to assess cetuximab cytotoxicity in DiFi cells incubated with cetuximab alone or together with the JNK inhibitor SP600125 (SP) or the p38 inhibitor SB202190 (SB). (C) Top panel: kinase assay to test p38 activity (performed with immunoprecipitated P-p38) in cells incubated with $0.5 \mu \mathrm{g} \mathrm{ml}{ }^{-1}$

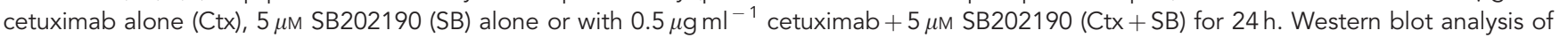
phosphorylated ATF2. Lower panels: western blot analysis of P-p38 and total p38 expression level in DiFi cells incubated with $0.5 \mu \mathrm{gml} \mathrm{m}^{-1}$ cetuximab alone (Ctx), $5 \mu \mathrm{m} \mathrm{SB202190} \mathrm{(SB)} \mathrm{alone} \mathrm{or} 10 \mu \mathrm{g} \mathrm{ml}^{-1}$ cetuximab $+5 \mu \mathrm{m} \mathrm{SB202190} \mathrm{(Ctx}+$ SB) for $24 \mathrm{~h}$. Equal loading is shown by tubulin (Tub). (D) Western blot analysis of AKT, P-AKT, ERK and P-ERK in DiFi cells incubated with $10 \mu \mathrm{g} \mathrm{ml}^{-1}$ cetuximab alone (Ctx), $5 \mu \mathrm{m}$ SB202190 (SB) alone or with $0.5 \mu \mathrm{g} \mathrm{ml}^{-1}$ cetuximab $+5 \mu \mathrm{M} \mathrm{SB202190}(\mathrm{Ctx}+\mathrm{SB})$ for $24 \mathrm{~h}$. Equal loading is shown by tubulin. NT, not treated. ${ }^{\star \star} P<0.01$. (E) Tumour growth inhibition experiment assessed in nude mice xenografted with DIFI cells and treated with SB202190, cetuximab or cetuximab + SB202190.

downregulated by ShRNA (Shp38 $\alpha 1$ and Shp38 $\alpha 2$; Figure 2A, left panels) compared with control cells (shLuc), as indicated by their significantly different $\mathrm{IC}_{50}$ values (ShLuc: $41.7 \mathrm{~nm}$; Shp38 $\alpha 1$ : 67.2 nM, $P$-value: 0.008 ; Shp38 2 : $74.5 \mathrm{nm,} P$-value: 0.032 ; Figure 2A, right panel)

We thus asked whether p38 could also be involved in the effect of other drugs targeting EGFR, such as the two tyrosine kinase inhibitors (TKI) lapatinib (EGFR and HER2 inhibitor) and erlotinib (EGFR inhibitor). Using the SRB assay and the p38 inhibitor SB202190, we found that the cytotoxic activity of lapatinib (Figure 2B) and erlotinib (Figure 2C) in DiFi cells was significantly reduced when they were associated with SB202190, as shown by their $\mathrm{IC}_{50}(680 \mathrm{~nm}$ for lapatinib alone and $1385 \mathrm{~nm}$ for lapatinib + SB202190, $P$-value: 0.0007; $150 \mathrm{~nm}$ for erlotinib alone and $300 \mathrm{~nm}$ for erlotinib + SB202190, $P$-value: 0.0006$)$. These results indicate that CRC cell sensitivity to cetuximab and anti-EGFR TKIs is dependent, at least in part, on p38 activity.

We then confirm the effect of p38 downregulation or inhibition on cetuximab cytotoxic effect on three other KRAS WT CRC cell lines: LIM1215 (Figures 2D and E), Caco2 and SW48 (Supplementary Figure 2). By using the SRB assay we showed that sensitivity to cetuximab was reduced in LIM1215 cells in which p38 was downregulated by ShRNA (Shp38 $\alpha 1$ and Shp38 2 ; Figure 2D, left panels) compared with control cells (shLuc). Moreover, we showed that cetuximab cytotoxicity was reduced following p38 inhibition with SB202190 compared with when used alone in LIM1215 (Figure 2E) and Caco2 and SW48 cells (Supplementary Figures $2 \mathrm{~A}$ and $\mathrm{C}$ ). Finally, we also confirm the effect of p38 activity inhibition on cetuximab sensitivity in vivo in Caco2 cells (Supplementary Figure 2B).
The MAPK p38 participates in the apoptotic and antiproliferative effects of cetuximab. We then investigated whether p38 role in cetuximab effect involves increase of cell death or inhibition of cell proliferation. Immunoblot analysis of cleavedcaspase 3 expression after incubation of DiFi cells with increasing doses of cetuximab for $24 \mathrm{~h}$ indicated that $1 \mu \mathrm{g} \mathrm{ml}^{-1}$ cetuximab was sufficient to induce caspase cleavage (Figure $3 \mathrm{~A}$ ). We then assessed apoptosis using increasing concentrations of cetuximab for $48 \mathrm{~h}$ with two other assays: (i) identification of Annexin $\mathrm{V}$-positive cells (Figure 3B, upper panels), representative of early apoptosis, and (ii) quantification of cells in the subG1 phase (Figure 3B, lower panels), representative of late apoptosis. The results of these assays indicated that apoptosis of DiFi cells was induced by $0.5 \mu \mathrm{g} \mathrm{ml}^{-1}$ cetuximab (24\% Annexin V-positive cells and $24.3 \%$ subG1 cells) and the percentage of apoptotic cells increased with the concentration of cetuximab. These experiments demonstrate unequivocally that cetuximab induces apoptosis in DiFi cells.

We then analysed the combined effect of cetuximab $\left(0.5 \mu \mathrm{g} \mathrm{ml}^{-1}\right)$ and SB202190 on apoptosis using the three methods described above (Figures 3C-E). Cetuximab alone induced apoptosis in DiFi cells, while SB202190 alone had no effect. Conversely, when associated with cetuximab, SB202190 reduced cetuximab-induced apoptosis. Specifically the percentage of Annexin V-labelled cells (Figure 3C) and subG1 cells (Figure 3D) decreased from 24\% and 29\% (cetuximab) to $12 \%$ and $13 \%$ (cetuximab + SB202190), respectively, ( $P$-value: $\left.2 \times 10^{-7}\right)$. Similarly, immunoblot analysis (Figure 3E) showed that induction of caspase 3 cleavage by cetuximab was reduced when SB202190 was associated. These results demonstrate that the MAPK p38 contributes to the apoptotic effect of cetuximab in DiFi cells. 
A
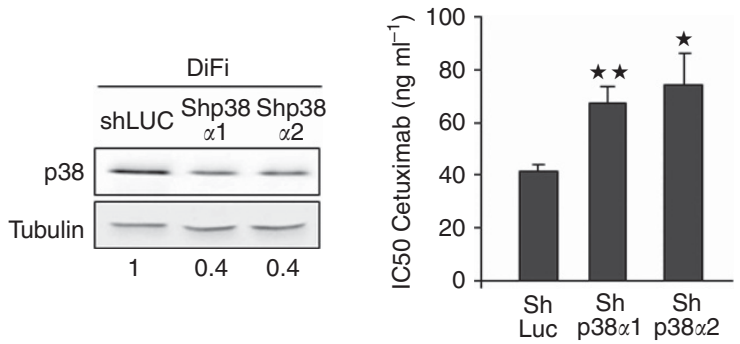

D

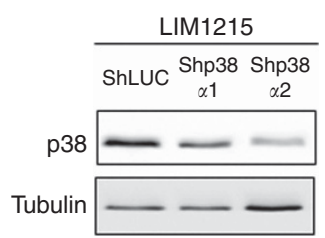

B

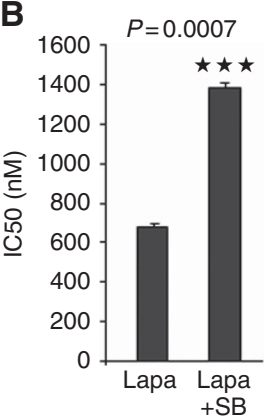

C

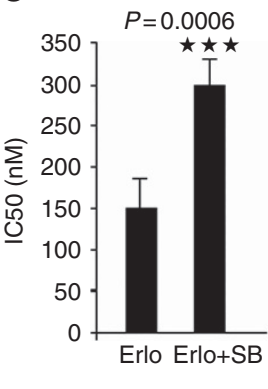

E

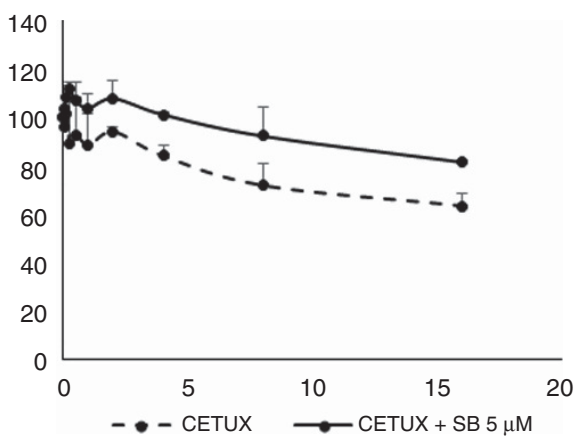

Figure 2. The MAPK p38 is necessary for the cytotoxic effect of EGFR-targeted therapies. (A) Left panel: western blot analysis of p38 $\alpha$ expression in DiFi cells transduced with ShRNAs against $p 38 \alpha$ (Shp38 $\alpha 1$ and Shp38 $\alpha 2$ ) or against Luciferase (ShLuc; control). Equal loading is shown by tubulin. Right panel: SRB assays to assess cetuximab cytotoxicity in DiFi cells transduced with two different ShRNAs against p38 $\alpha$ (Shp38 1 and Shp38 2 2). (B) SRB assays to assess the cytotoxicity of lapatinib (Lapa) or erlotinib (Erlo); (C) alone or in combination with $5 \mu$ M SB202190 (SB, p38 inhibitor) in DiFi cells. NT, not treated. ${ }^{\star} P<0.05,{ }^{*} P<0.01,{ }^{*} * P<0.001$. (D) Left panel: western blot analysis of p38 $\alpha$ expression in LIM1215 cells transduced with ShRNAs against $p 38 \alpha$ (Shp38 1 and Shp38 2 ) or against Luciferase (ShLuc; control). Equal loading is shown by tubulin. Right panel: SRB assays to assess cetuximab cytotoxicity in LIM1215 cells transduced with ShRNA against p38 $\alpha$. (E) SRB assays to assess the cytotoxicity of cetuximab alone or in combination with $5 \mu \mathrm{M}$ SB202190 (SB, p38 inhibitor) in LIM1215 cells.

Next, we tested the effect of cetuximab and SB202190 on cell proliferation and cell cycle. Cetuximab inhibited cell proliferation as indicated by the reduction of EdU-positive DiFi cells (from 75\% in untreated cells to $10.7 \%$ in cetuximab-treated cells; $P$-value: $3.1 \times 10^{-7}$; Figure $\left.3 \mathrm{~F}\right)$. Cetuximab inhibition of cell proliferation was significantly reduced when SB202190 was also added $(40.4 \%$ EdU-positive cells compared with only $10.7 \%$ with cetuximab alone), indicating that p38 is also necessary for cetuximab antiproliferative effect. Furthermore, cetuximab-induced accumulation of cells in the G1 phase (from 56\% in untreated to $74 \%$ in cetuximab-treated DiFi cells, $P$-value: 0.01 ; Figure $3 \mathrm{G}$ ) was not observed when SB202190 was associated with cetuximab (61\% of cells in G1 in cetuximab + SB202190 DiFi cells, $P$-value: 0.03 compared with cetuximab). Altogether these results demonstrate that the MAPK p38 is necessary for cetuximab functional activity and is involved in apoptosis induction and proliferation inhibition.

Cetuximab activates the transcription factor FOXO3A in a MAPK p38-dependent manner. We then tried to identify transcription factor(s) involved in cetuximab effect on cell growth and apoptosis. As cetuximab inhibits the AKT and ERK signalling pathways and activates the MAPK p38 pathway, we focused on FOXO3a, because it is inactivated by ERK and AKT and can be activated by p38 (Roy et al, 2010; Ho et al, 2012). Phosphorylation by ERK and AKT results in FOXO3a cytoplasmic accumulation and subsequent degradation, while phosphorylation by p38 leads to FOXO3a nuclear re-localisation and activation (Ho et al, 2012). Immunoblot analysis of cytoplasmic and nuclear extracts from $\mathrm{DiFi}$ cells treated with cetuximab showed that FOXO3a was detected easily in the cytoplasmic fraction (Figure 4A, upper left panel), but was hardly detectable in the nuclear fraction. Therefore, to enrich FOXO3a in the nuclear fraction we performed immunoprecipitation experiments with an antibody targeting FOXO3a and then immunoblot analysis (Figure 4A, upper right panel). We could thus detect FOXO3a also in the nucleus of nontreated cells, and show that, after incubation with cetuximab for $1 \mathrm{~h}, \mathrm{FOXO} 3 \mathrm{a}$ decreased in the cytoplasm and increased in the nucleus.

As p38 can phosphorylate and activate FOXO3a (Ho et al, 2012) and p38 is activated by cetuximab, we investigated whether p38 phosphorylated FOXO3a in DiFi cells incubated with cetuximab. Immunoprecipitation of FOXO3a in nuclear extracts after treatment with cetuximab or cetuximab + SB202190 (Figure 4A, lower panels) showed that nuclear accumulation of FOXO3a after cetuximab treatment was inhibited when the p38 inhibitor SB202190 was added. Moreover, immunoblotting of the immunoprecipitated proteins with an antibody against FOXO3a phosphorylated at ser-7 (p38-specific phosphorylation of FOXO3a) showed that phosphorylated FOXO3a on ser-7 was enriched in cells incubated with cetuximab, whereas it was diminished when SB202190 was associated with cetuximab. Altogether, these results indicate that cetuximab-induced nuclear accumulation of FOXO3a is dependent on p38 activity. To confirm this result, we examined by immunofluorescence staining the subcellular localisation of FLAG-tagged wild-type FOXO3a in DiFi cells incubated or not with cetuximab, SB202190 or both (Figure 4B). The efficacy of transfection was low, but we could detect some cells expressing tagged FOXO3a. Consistent with the previous results, FOXO3a was localised predominantly in the cytoplasm in untreated cells and almost exclusively in the cytoplasm in SB202190-treated cells. Conversely, FOXO3a was predominantly in the nucleus after incubation with cetuximab, but was delocalised to the cytoplasm when SB202190 was associated with cetuximab. On the other hand, in cells that express a ser-7-phosphorylation-deficient FLAG- 
A

\begin{tabular}{|c|c|c|c|c|c|}
\hline \multirow{4}{*}{$\begin{array}{r}\text { Cleaved } \\
\text { Casp3 }\end{array}$} & \multicolumn{5}{|c|}{$\mathrm{Ctx}\left(\mu \mathrm{g} \mathrm{ml}^{-1}\right)$} \\
\hline & NT & 0.01 & 0.1 & 1 & 10 \\
\hline & & & & 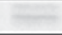 & 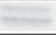 \\
\hline & 0 & 0 & 0 & 2.1 & 2.6 \\
\hline p-p38 & & & & - & - \\
\hline & 0.1 & 0.1 & 0.1 & 2.1 & 1.7 \\
\hline
\end{tabular}

C

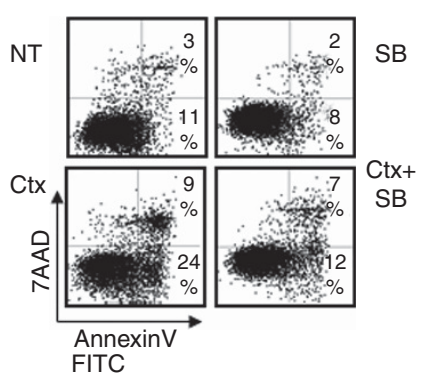

F

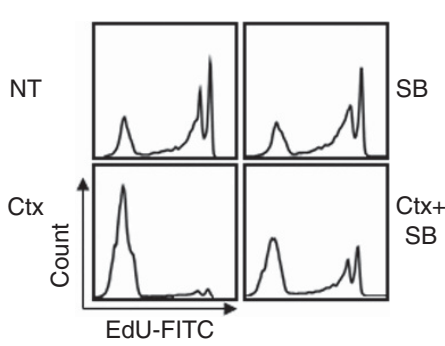

B
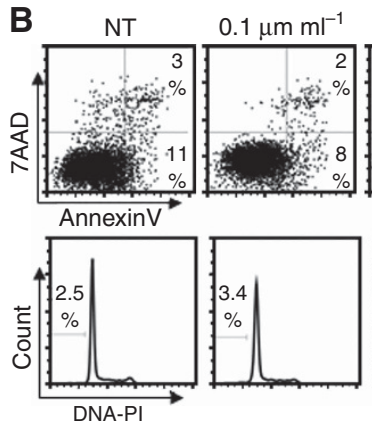

D

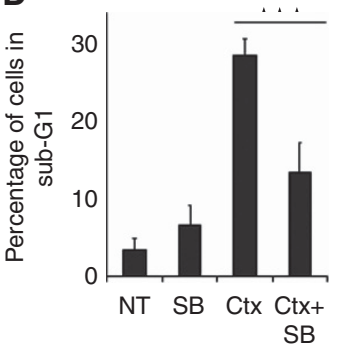

SB

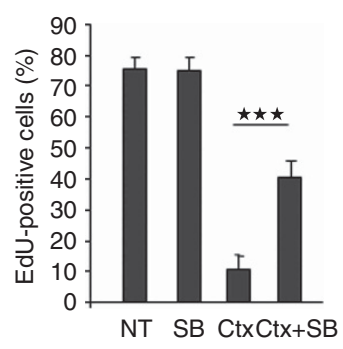

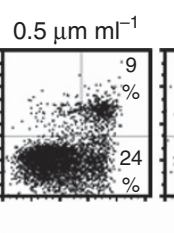

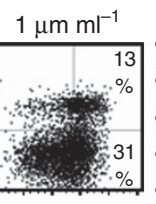

$5 \mu \mathrm{m} \mathrm{ml}^{-1}(\mathrm{Ctx})$
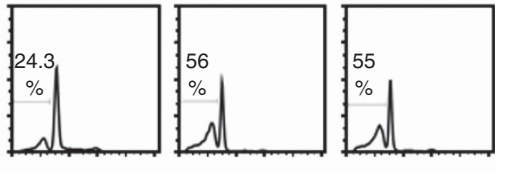

E

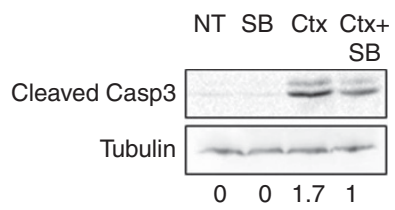

\section{G}

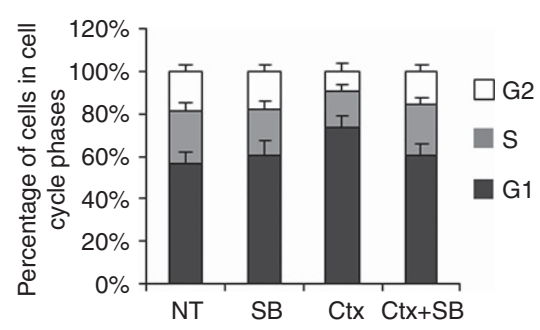

Figure 3. The MAPK p38 participates in cetuximab apoptotic and anti-proliferative effect. (A) Western blot analysis of cleaved-caspase 3 (Cleaved Casp3) or phospho-p38 (p-p38) in DiFi cells incubated with increasing concentrations of cetuximab (Ctx, $0.01,0.1,1$ and $10 \mu \mathrm{g} \mathrm{ml}^{-1}$ ) for $48 \mathrm{~h}$. Equal loading was assessed with an anti-tubulin antibody. (B) DiFi cells were incubated with increasing concentrations of cetuximab (Ctx) for $48 \mathrm{~h}$ and apoptosis was determined by quantifying the number of 7AAD-negative and Annexin V-positive cells with a FC500 flow cytometer (top panels) or by quantifying the proportion of cells in the subG1 phase of the cell cycle (lower panels). (C) Quantification of apoptosis in DiFi cells incubated with $0.5 \mu \mathrm{g} \mathrm{ml}^{-1}$ cetuximab (Ctx) alone, $5 \mu \mathrm{m} \mathrm{SB202190}$ alone (SB) or $0.5 \mu \mathrm{g} \mathrm{ml}^{-1}$ cetuximab $+5 \mu \mathrm{m} \mathrm{SB202190} \mathrm{(Ctx+SB)} \mathrm{for} 48 \mathrm{~h}$ by calculating the number of 7AAD-negative and Annexin V-positive cells with a FC500 flow cytometer or (D) the proportion of cells in the subG1 phase of the cell cycle. (E) Western blot analysis of cleaved-caspase 3 (Cleaved Casp3) in DiFi cells incubated with $10 \mu \mathrm{g} \mathrm{ml}^{-1} \mathrm{cetuximab}(\mathrm{Ctx})$ alone, $5 \mu \mathrm{m} \mathrm{SB202190} \mathrm{(SB)} \mathrm{alone} \mathrm{or} 10 \mu \mathrm{g} \mathrm{ml}^{-1}$ cetuximab $+5 \mu \mathrm{m} \mathrm{SB202190} \mathrm{(Ctx+SB)} \mathrm{for} 24 \mathrm{~h}$. Equal loading was assessed with an anti-tubulin antibody. (F) Cell proliferation was analysed by quantifying the percentage of Edu-labelled DiFi cells after incubation with $0.5 \mu \mathrm{g} \mathrm{ml}{ }^{-1} \mathrm{cetuximab}$ (Ctx) alone, $5 \mu \mathrm{m} \mathrm{SB202190} \mathrm{alone} \mathrm{(SB)} \mathrm{or} 0.5 \mu \mathrm{g} \mathrm{ml}^{-1}$ cetuximab $+5 \mu \mathrm{m}$ SB202190 (Ctx + SB) for $48 \mathrm{~h}$ (left panels). The histogram shows the mean of three experiments (right panel). (G) Cell cycle distribution in DiFi cells was assessed by quantifying propidium iodide staining with a FC500 flow cytometer after incubation with $0.5 \mu \mathrm{g} \mathrm{ml}^{-1}$ cetuximab (Ctx) alone, $5 \mu \mathrm{m} \mathrm{SB202190}$ alone (SB) or $0.5 \mu \mathrm{g} \mathrm{ml}^{-1}$ cetuximab $+5 \mu \mathrm{m} \mathrm{SB202190}$ $(\mathrm{Ctx}+\mathrm{SB})$ for $48 \mathrm{~h}$. NT, not treated. ${ }^{\star \star \star} \mathrm{P}<0.001$.

tagged FOXO3a mutant (FOXO3A-A7; Figure 4D), nuclear relocalisation of FOXO3a-A7 in response to cetuximab treatment was reduced compared with wild-type FOXO3a. These results show that FOXO3a can be activated by cetuximab in CRC cells and that this activation is dependent on its phosphorylation on ser-7 by p38 (Figure 4C, lower panel).

To determine whether FOXO3a is involved in cetuximab cytotoxic activity, we generated stable DiFi cell lines in which FOXO3a was knocked down with retroviruses that express three different anti-FOXO3a ShRNAs (F1 to F3). The F2 ShRNA efficiently reduced FOXO3a expression in DiFi cells (Figure 4C, upper panels) and this cell line was used for testing cetuximab cytotoxic activity by SRB assay. Cetuximab cytotoxicity was reduced in the ShFOXO3A-F2 Difi cell line compared with control cells (ShLuc), as indicated by the higher $\mathrm{IC}_{50}$ of cetuximab $\left(101 \mathrm{ng} \mathrm{ml}^{-1}\right)$ in F2 cells than in ShLuc cells $\left(68 \mathrm{ng} \mathrm{ml}^{-1} ; P\right.$-value: $0.005)$. The finding that sensitivity to cetuximab is reduced when
FOXO3a is downregulated indicates that FOXO3a is involved in the cytotoxic effect of cetuximab in CRC cells.

BIM and p27, downstream targets of FOXO3a, participate in cetuximab apoptotic effect. To identify FOXO3a target genes induced by cetuximab, and involved in the apoptotic and antiproliferative effect of cetuximab, we performed a proteome profiler analysis combined with specific immunoblot and qPCR assays. Proteome profiler identified two downstream targets of FOXO3a, BIM and p27, being specifically overexpressed upon cetuximab treatment and downregulated when SB202190 was added. RTqPCR analysis using DiFi cells incubated with cetuximab and/or SB202190 showed that BIM and $p 27$ were upregulated in DiFi cells treated with cetuximab (BIM: 2.8-fold, $P$-value: 0.0002, p27: 1.6fold, $P$-value: 0.0002 ), and that their upregulation was inhibited by co-incubation with SB202190 (BIM: 1.9-fold, $P$-value: 0.01; p27: 
A

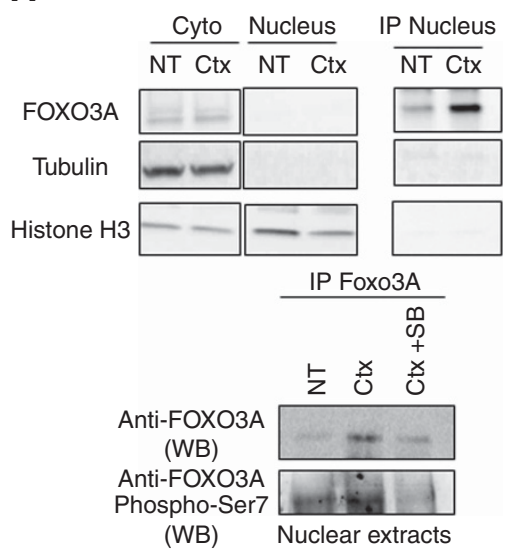

C
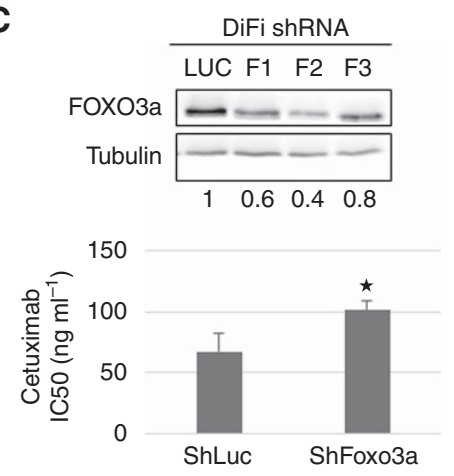

B

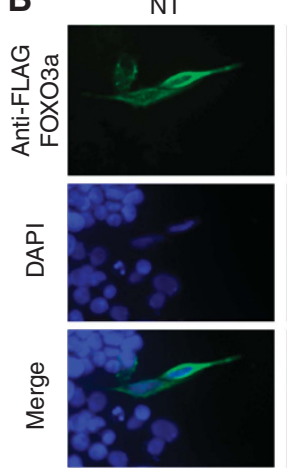

D
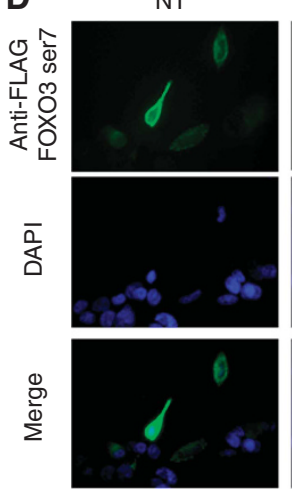

Ctx
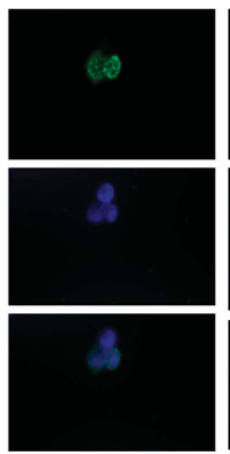

Ctx
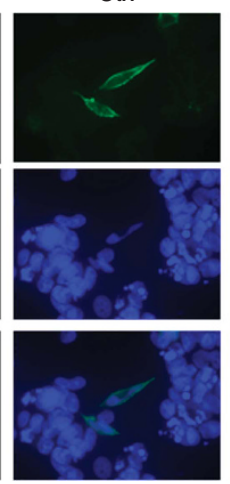

SB
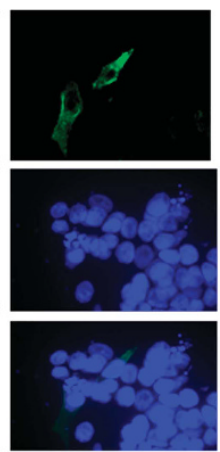

SB
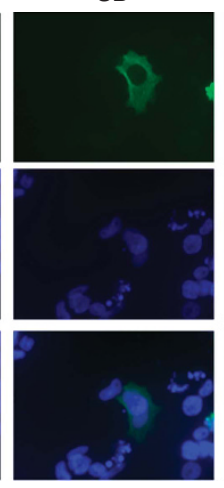

$\mathrm{Ctx}+\mathrm{SB}$

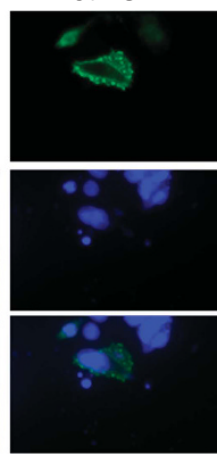

$\mathrm{Ctx}+\mathrm{SB}$

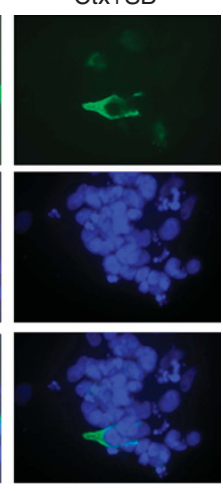

Figure 4. Cetuximab activates the transcription factor FOXO3a in a MAPK p38-dependent manner. (A) Western blot analysis of FOXO3a, tubulin and histone $\mathrm{H} 3$ in the cytoplasm, in the nucleus and after FOXO3a immunoprecipitation. DiFi cell were incubated with $10 \mu \mathrm{g} \mathrm{ml}{ }^{-1} \mathrm{cetuximab}(\mathrm{Ctx})$ for $1 \mathrm{~h}$ (top panels). Western blot analysis of FOXO3a and phospho-ser-7-FOXO3a in nuclear extracts after FOXO3a immunoprecipitation. DiFi cell were treated with $10 \mu \mathrm{g} \mathrm{ml}^{-1}$ cetuximab alone (Ctx) or $10 \mu \mathrm{g} \mathrm{ml}^{-1}$ cetuximab $\left.+5 \mu \mathrm{m} \mathrm{SB202190} \mathrm{(Ctx}+\mathrm{SB}\right)$ for $1 \mathrm{~h}$ (lower panels). (B) Detection of FLAG-tagged wild-type FOXO3a by immunofluorescence in DiFi cells incubated with $10 \mu \mathrm{g} \mathrm{ml}^{-1}$ cetuximab (Ctx), $5 \mu \mathrm{m} \mathrm{SB202190} \mathrm{(SB)} \mathrm{or}$ $10 \mu \mathrm{g} \mathrm{ml}^{-1}$ cetuximab $+5 \mu \mathrm{M} \mathrm{SB202190}(\mathrm{Ctx}+\mathrm{SB})$ for $1 \mathrm{~h}$. (C) Western blot analysis of FOXO3a expression in DiFi cells transduced with three different ShRNAs against FOXO3a (F1, F2 and F3) or against Luciferase (Luc; control). Equal loading is shown by tubulin expression (top panels). SRB assays to assess cetuximab cytotoxicity in DiFi cells transduced with the F2 ShRNA against FOXO3a (lower panel). (D) Detection of FLAGtagged mutant FOXO3a-7A by immunofluorescence in DiFi cells incubated with $10 \mu \mathrm{g} \mathrm{ml}^{-1}$ cetuximab (Ctx), $5 \mu \mathrm{M} \mathrm{SB202190} \mathrm{(SB)} \mathrm{or} 10 \mu \mathrm{g} \mathrm{ml}{ }^{-1}$ cetuximab $+5 \mu \mathrm{m}$ SB202190 $(\mathrm{Ctx}+\mathrm{SB})$ for $1 \mathrm{~h}$. NT, not treated. ${ }^{\star} P<0.05$.

1.1-fold, $P$-value: 0.004; Figure 5A). We confirmed these results at protein level by immunoblot analysis (Figure 5B).

We then generated stable DiFi cell lines in which BIM or $p 27$ was knocked down with retroviruses that express three different anti-BIM ShRNAs or one anti-p27 ShRNA. The ShRNA-BIM-2 and 3 efficiently reduced BIM expression in DiFi cells (Figure 5C, left panels) and these two stable cell lines were used to test cetuximab cytotoxicity by SRB assay. Cetuximab cytotoxicity was reduced in DiFi cells in which BIM was downregulated compared with controls (ShLuc), as indicated by their $\mathrm{IC}_{50}\left(53 \mathrm{ng} \mathrm{ml}^{-1}\right.$ in ShLuc and $73 \mathrm{ng} \mathrm{ml}^{-1}$ in ShBIM2 cells, $P$-value: $0.02 ; 71 \mathrm{ng} \mathrm{ml}^{-1}$ ShBIM3, $P$-value: 0.04). Of note, cetuximab $\mathrm{IC}_{50}$ values in $\mathrm{DiFi}$ ShBIM cells and in control cells treated with cetuximab + SB202190 were similar, indicating that BIM loss has the same biological effect than p38 inhibition. Similar results were obtained with DiFi-Shp27 cells (cetuximab $\mathrm{IC}_{50}: 58.5 \mathrm{ng} \mathrm{ml}^{-1}$ in DiFi-Shp27 and $42 \mathrm{ng} \mathrm{ml}^{-1}$ in ShLuc cells, $P$-value: 0.02; Figure 5D). These results show that cetuximab induces FOXO3a and the transcription of its downstream targets $B I M$ and $p 27$ that are implicated in the cytotoxic effect of cetuximab in CRC cells.

The expression levels of FOXO3A and p38 are linked to impaired response to cetuximab in patients with CRC. To address the clinical relevance of p38 activation in the response to cetuximab treatment, FOXO3a and p38 mRNA expression levels were analysed in a transcriptome data set created by KhambataFord et al (2007), (GSE5851) from 80 patients with mCRC and treated with cetuximab monotherapy. Among patients with mCRC harbouring WT KRAS $(n=43)$, FOXO3a and p38 expression were higher in cetuximab responders $(n=20)$ than in non-responders $(n=19 ; P=0.009$ for FOXO3a and $P=0.04$ for $\mathrm{p} 38$; Figure 6A). This is in agreement with our in vitro and in vivo results showing that FOXO3a and p38 are required for cetuximab full activity.

Recently, different CRC molecular subtypes have been defined based on the combined analysis of their gene-expression profile (Schlicker et al, 2012; Budinska et al, 2013; De Sousa et al, 2013; Marisa et al, 2013; Sadanandam et al, 2013; Roepman et al, 2014). The association between CRC molecular subtypes and response to cetuximab has been evaluated using the Sadanandam and De Sousa E Melo's classifications (De Sousa et al, 2013; Sadanandam et al, 2013) and the Marisa's classification by our group (Del Rio et al, manuscript submitted). We found that in the 43 patients with mCRC harbouring WT KRAS from the Khambata-Ford data set, patients with a cancer classified as C1 or C5 (Marisa's subtypes) had a significantly longer progression-free survival than patients with other subtypes (Del rio et al, manuscript submitted). Similarly, the Sadanandam's TA subtype was associated with a better response to cetuximab (Sadanandam et al, 2013) and 

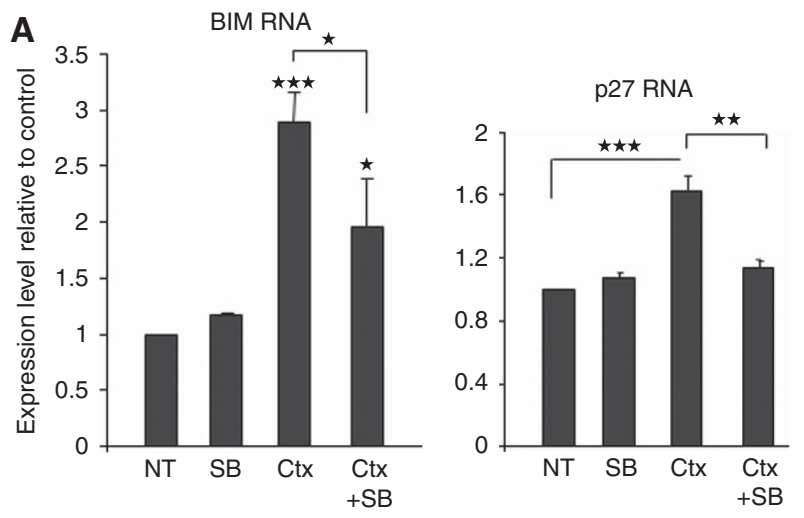

B
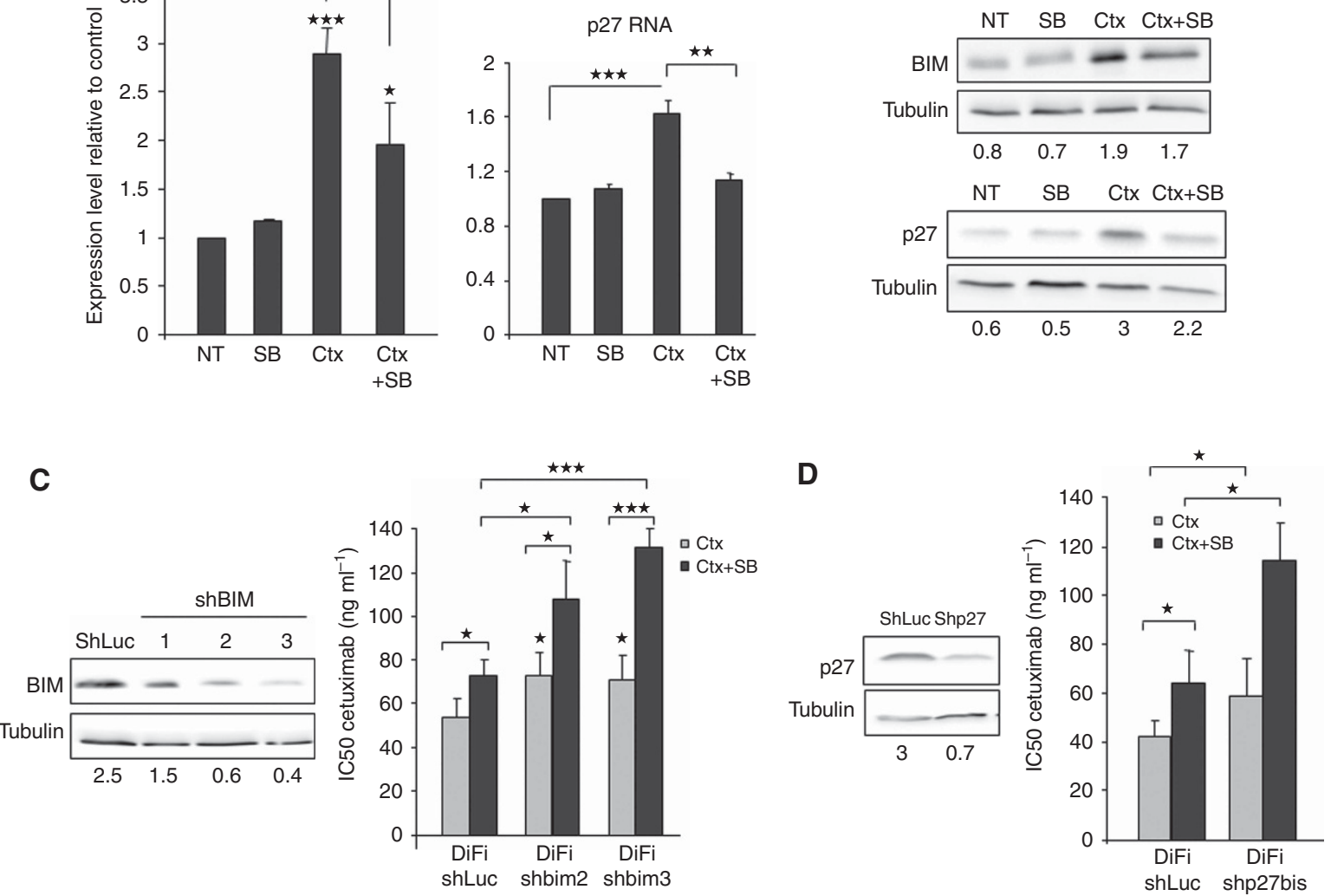

Figure 5. BIM and p27, downstream targets of FOXO3a, participate in cetuximab apoptotic effect. (A) RT-qPCR quantification of BIM (left panel) and p27 transcripts (right panel) in DiFi cells incubated with $10 \mu \mathrm{g} \mathrm{ml}^{-1}$ cetuximab (Ctx) alone, $5 \mu \mathrm{m} \mathrm{SB202190} \mathrm{alone} \mathrm{(SB)} \mathrm{or} 10 \mu \mathrm{g} \mathrm{ml}{ }^{-1}$ cetuximab $+5 \mu \mathrm{M}$ SB202190 (Ctx + SB) for $24 \mathrm{~h}$. (B) Western blot analysis of BIM and p27 expression in DiFi cells incubated with $10 \mu \mathrm{gml}{ }^{-1}$ cetuximab (Ctx) alone, $5 \mu \mathrm{m} \mathrm{SB202190}$ alone (SB) or $10 \mu \mathrm{g} \mathrm{ml}{ }^{-1}$ cetuximab $+5 \mu \mathrm{m} \mathrm{SB202190} \mathrm{(Ctx}+$ SB) for $24 \mathrm{~h}$. Equal loading was assessed with an anti-tubulin antibody. (C) Western blot analysis of BIM expression in DiFi cells transduced with three different ShRNAs directed against BIM (ShBIM1, ShBIM2 and ShBIM3) or against Luciferase (ShLuc; control). Equal loading is shown by tubulin expression (left panels). SRB assays to assess cetuximab cytotoxicity in DiFi cells transduced with ShRNAs against BIM (shbim2 and shbim3) or Luciferase (shLUC) and incubated with

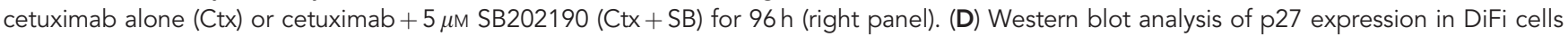
transduced with ShRNAs against p27 (Shp27) or against Luciferase (ShLuc; control). Equal loading is shown by tubulin expression (left panels). SRB assays to assess cetuximab cytotoxicity in DiFi cells that express ShRNAs against p27 and incubated with cetuximab alone (Ctx) or cetuximab $+5 \mu \mathrm{M}$ SB202190 (Ctx $+\mathrm{SB})$ for $96 \mathrm{~h}$ (right panel). ${ }^{\star} P<0.05,{ }^{\star} * P<0.01,{ }^{\star \star \star} P<0.001$.

De Sousa E Melo's CCS1 subtype with better disease control rate (De Sousa et al, 2013). Here, we analysed FOXO3a and p38 geneexpression level in the different CRC molecular subtypes and found the highest expressions in the C1, C5 $\left(P=8.410^{-5}\right.$ for FOXO3a, $P=0.019$ for p38), CCS1 $(P=0.0013$ for FOXO3a, $P=0.0054$ for $\mathrm{p} 38)$ and TA $(P=0.0053$ for FOXO3a, $P=0.016$ for p38) subtypes (Figure 6B). These results indicate that high FOXO3a and p38 expression are associated with a better response to cetuximab and good outcome in these three classifications.

Analysis of FOXO3a and MAPK14 expression has finally been evaluated on the recently published consensus subtypes (Supplementary Figure 3). This figure shows that FOXO3a and MAPK p38 are highly expressed in the CMS2 subtype. The CMS2 subtypes is called 'canonical' and correspond to the CCS1 of De Sousa's, TA and Enterocyte of Sadanandam and C1 and C5 of Marisa's. This result is in accordance with the data obtained with the three other classifications.

Altogether, our findings suggest that FOXO3a and p38 expression levels are markers of cetuximab response in CRC and the variations in their expression level may partially explain the different sensitivity of CRC subtypes to this drug.

\section{DISCUSSION}

In the present study, we show for the first time in CRC cells that p38 phosphorylation is increased upon cetuximab treatment. We demonstrate the role of p38, FOXO3a, BIM and p27 in cetuximab cytotoxic and cytostatic effects. Moreover, we found that FOXO3a and p38 expression levels are higher in responder patients, indicating that FOXO3A and p38 could be used as specific biomarkers of cetuximab efficacy in patients with WT KRAS CRC.

Our study shows that upon cetuximab treatment, p38 can activate FOXO3a. Ho et al (2012) have recently reported that p38 phosphorylates directly FOXO3A on ser-7, promoting its nuclear translocation and activation. This new p38 target protein is specific, because the other mammalian members of the FOXO family (FOXO1, FOXO4 and FOXO6) do not harbour this phosphorylation site. Moreover, FOXO3a phosphorylation on ser-7 is exclusively mediated by p38, because inhibition of JNK, PI3K and ERK has no effect on this phosphorylation. These data reinforce the role of p38 in FOXO3a activation after cetuximab treatment. While most FOXO3a phosphorylation sites have 
A
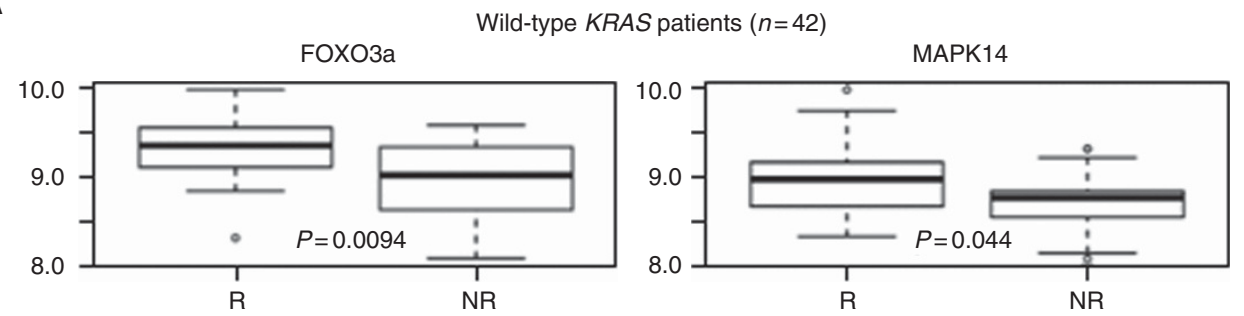

B

FOXO3a
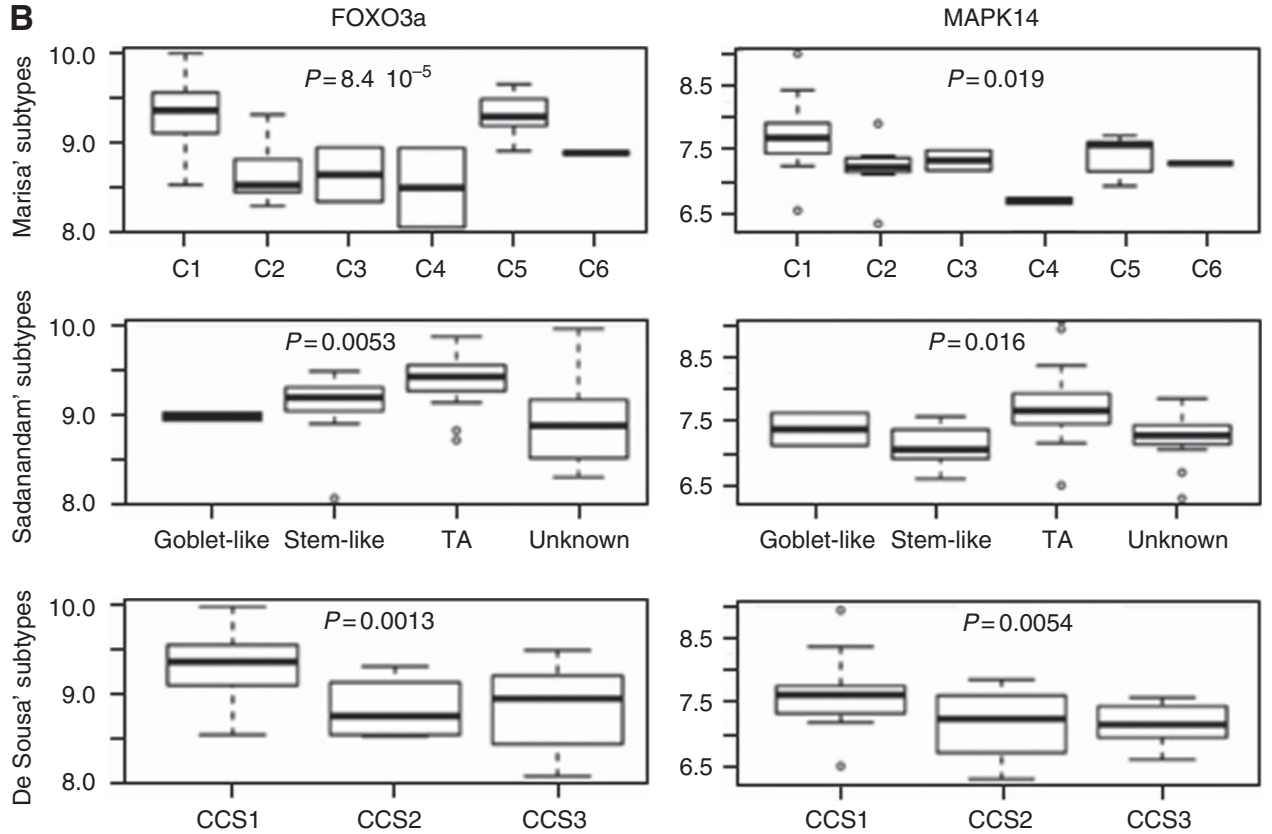

Figure 6. FOXO3a and p38 are expressed in cetuximab-responder patients. (A) Box plot depiction of FOXO3a and p38 (MAPK14) mRNA expression in CRC samples from patients with mCRC harbouring WT KRAS and treated with cetuximab monotherapy (Khambata-Ford et al (2007); GSE5851 data set). R, cetuximab responders $(n=20)$ and NR, cetuximab non-responders $(n=19)$. (B) Box plot representation of FOXO3a and p38 (MAPK14) mRNA expression in the same CRC samples described in $\mathbf{A}$ and classified according to the molecular classifications by Marisa et al (2013) (upper panels), Sadanandam et al (2013) (middle panels) and De Sousa et al (2013) (lower panels).

inhibitory effects on its activity and nuclear localisation, ser-7phosphorylation is associated with FOXO3a nuclear accumulation and the subsequent induction of apoptosis and inhibition of cell proliferation.

While FOXO3a activation upon incubation of CRC cells with cetuximab was never reported, some publications have shown that drugs targeting the EGFR signalling, particularly erlotinib in cells from patients with chronic obstructive pulmonary disease (Ganesan et al, 2013) or gefitinib, lapatinib and trastuzumab in breast cancer cells (Real et al, 2005; Hegde et al, 2007; Krol et al, 2007), can activate FOXO3a, leading to cell death and/or cell cycle arrest. These results indicate that cell death and the antiproliferative effects induced by EGFR inhibition can be attributed, at least in part, to the specific activation of FOXO3a and that, as a consequence, FOXO3a nuclear localisation could become a useful biomarker of the therapeutic success of EGFR inhibitors.

However, our results contradict the work by Simone's group showing that p38 inhibition (and not p38 activation like in the present study) in CRC cells induces FOXO3a activation and subsequently autophagy, cell death and tumour growth reduction (Chiacchiera et al, 2012). They demonstrated that p38 inhibition leads to a decrease in intracellular ATP levels and activation of AMP-activated protein kinase (AMPK). AMPK in turn activates FOXO3a (phosphorylation at Thr-179, Ser- 399, Ser-413, Ser-555, Ser-588 and Ser-626) without affecting its cytoplasmic/nuclear distribution. These differences may be linked to the specific
FOXO3a phosphorylation. We have shown that p38-specific ser-7phosphorylation of FOXO3a is essential because the ser-7phosphorylation-defective FOXO3a mutant could not localise to the nucleus any longer upon cetuximab treatment. Moreover, Chiacchiera et al (2012) used KRAS or BRAF mutated CRC cells and chemotherapy, whereas we used an anti-EGFR antibody in wild-type KRAS CRC cells.

In conclusion, here we show that p38 participates in the cytotoxic and cytostatic effect of cetuximab in CRC cells KRAS WT. Altogether our results highlight a new pathway induced by cetuximab in wild-type KRAS CRC cells. We propose a model of p38 role in cetuximab-induced cytotoxicity. In the absence of cetuximab (Supplementary Figure 1A), EGF binds to EGFR and activates the AKT and ERK signalling pathways, which are involved in cell survival and proliferation. AKT and ERK phosphorylate FOXO3a and this phosphorylation leads to FOXO3a re-localisation from the nucleus to the cytoplasm and to its degradation. The two FOXO3a target genes BIM and $p 27$ are therefore not transcribed any longer and this leads to cell survival and cell proliferation. On the other hand, cetuximab binding to EGFR (Supplementary Figure 1B) leads to inhibition of AKT and ERK signalling, relieving their negative effect on FOXO3a. At the same time, cetuximab activates the MAPK p38 that further inhibits ERK signalling and activates FOXO3a by specific phosphorylation on serine 7. FOXO3a activation combined with the lack of ERK and AKT signalling leads to FOXO3a nuclear accumulation, 
transcription of its target genes, among which there are BIM and $p 27$, and induction of apoptosis and inhibition of proliferation.

The molecular mechanism of p38 activation via cetuximab has not been identified. A possible mechanism of cetuximab induction of p38 phosphorylation is via the protein phosphatase MKP-1. MKP-1 has been shown to be activated by EGFR pathway, transcriptionally and post-translationally (Takeuchi et al, 2009). Once activated, MKP-1 inhibits phosphorylation of MAPK, whose p38 and JNK is part. So, one can imagine that cetuximab will inhibit MKP-1, leading to an enhanced p38 and JNK phosphorylation and activation. Figure $1 \mathrm{~B}$ is consistent with this hypothesis since cetuximab leads to activation of p38 and JNK. In agreement with this explanation, Montagut et al (2010) demonstrated in 2010 that MKP-1 overexpression impairs the response to cetuximab in mCRC patients. Our interpretation could be that overexpression of MKP-1 inhibits p38 activity and then prevent cetuximab maximal effect. Our results on CRC patients samples showing that the overexpression of $\mathrm{p} 38$ correlates with a good response to cetuximab, is in accordance with this study.

The results in clinical samples validate the role of FOXO3a and p38 in cetuximab mechanism of action. Indeed, high FOXO3a and p38 levels are associated with better disease control in patients treated with cetuximab, because cetuximab therapy is more likely to be effective in tumours expressing high levels of FOXO3a and p38.

We and others have previously shown that p38 is involved in the mechanism of action of other anti-cancer drugs. For example, inhibition of p38 sensitises colon cancer cells to SN38 (Paillas et al, 2011, 2012), 5-fluorouracil (Yang et al, 2011), sorafenib (Grossi et al, 2012) and cisplatin (Germani et al, 2014). Moreover, p38 contributes to the cytotoxic effect of oxaliplatin (Chiu et al, 2008; Liu et al, 2010; Dey and Liu, 2012). Altogether, these results indicate that p38 is a major player in the treatment of CRC.

\section{ACKNOWLEDGEMENTS}

We thank the Montpellier RIO Imaging facility for flow cytometry experiments, in particular Nadia Vié. The Supplementary Figure 1 was generated using the Servier medical art (www.servier.fr). This work was supported by INSERM and ICM Val D'Aurelle. LM had a PhD studentship from the French government. EC has a $\mathrm{PhD}$ studentship from the Labex MabImprove. AT had a MabImprove post-doctoral fellowship. The research leading to this publication was funded by the French National Research Agency under the programme 'Investissements d'avenir' Grant Agreement LabEx MAbImprove: ANR-10-LABX-53 and SIRIC (INCA-DGOS-Inserm 6045).

\section{CONFLICT OF INTEREST}

The authors declare no conflict of interest.

\section{REFERENCES}

Amado RG, Wolf M, Peeters M, Van Cutsem E, Siena S, Freeman DJ, Juan T, Sikorski R, Suggs S, Radinsky R, Patterson SD, Chang D (2008) Wild-type KRAS is required for panitumumab efficacy in patients with metastatic colorectal cancer. J Clin Oncol 26: 1626-1634.

Biggs WH, Meisenhelder J, Hunter T, Cavenee WK, Arden KC (1999) Protein kinase B/Akt-mediated phosphorylation promotes nuclear exclusion of the winged helix transcription factor FKHR1. Proc Natl Acad Sci USA 96: $7421-7426$

Budinska E, Popovici V, Tejpar S, D’Ario G, Lapique N, Sikora KO, Di Narzo AF, Yan P, Hodgson JG, Weinrich S, Bosman F, Roth A, Delorenzi M (2013) Gene expression patterns unveil a new level of molecular heterogeneity in colorectal cancer. J Pathol 231: 63-76.
Candeil L, Gourdier I, Peyron D, Vezzio N, Copois V, Bibeau F, Orsetti B, Scheffer GL, Ychou M, Khan QA, Pommier Y, Pau B, Martineau P, Del Rio M (2004) ABCG2 overexpression in colon cancer cells resistant to SN38 and in irinotecan-treated metastases. Int J Cancer 109: 848-854.

Chiacchiera F, Grossi V, Cappellari M, Peserico A, Simonatto M, Germani A, Russo S, Moyer MP, Resta N, Murzilli S, Simone C (2012) Blocking p38/ ERK crosstalk affects colorectal cancer growth by inducing apoptosis in vitro and in preclinical mouse models. Cancer Lett 324: 98-108.

Chiu S-J, Chao J-I, Lee Y-J, Hsu T-S (2008) Regulation of gamma-H2AX and securin contribute to apoptosis by oxaliplatin via a p38 mitogen-activated protein kinase-dependent pathway in human colorectal cancer cells. Toxicol Lett 179: 63-70.

Cuenda A, Rousseau S (2007) p38 MAP-kinases pathway regulation, function and role in human diseases. Biochim Biophys Acta 1773: 1358-1375.

Cunningham D, Humblet Y, Siena S, Khayat D, Bleiberg H, Santoro A, Bets D, Mueser M, Harstrick A, Verslype C, Chau I, Van Cutsem E (2004) Cetuximab monotherapy and cetuximab plus irinotecan in irinotecanrefractory metastatic colorectal cancer. $N$ Engl J Med 351: 337-345.

De Sousa E, Melo F, Wang X, Jansen M, Fessler E, Trinh A, de Rooij LP, de Jong JH, de Boer OJ, van Leersum R, Bijlsma MF, Rodermond H, van der Heijden M, van Noesel CJ, Tuynman JB, Dekker E, Markowetz F, Medema JP, Vermeulen L (2013) Poor-prognosis colon cancer is defined by a molecularly distinct subtype and develops from serrated precursor lesions. Nat Med 19: 614-618.

Dey H, Liu Z-R (2012) Phosphorylation of p68 RNA helicase by p38 MAP kinase contributes to colon cancer cells apoptosis induced by oxaliplatin. BMC Cell Biol 13: 27.

Ferlay J, Shin H-R, Bray F, Forman D, Mathers C, Parkin DM (2010) Estimates of worldwide burden of cancer in 2008: GLOBOCAN 2008. Int $J$ Cancer 127: 2893-2917.

Ganesan S, Unger BL, Comstock AT, Angel KA, Mancuso P, Martinez FJ, Sajjan US (2013) Aberrantly activated EGFR contributes to enhanced IL-8 expression in COPD airways epithelial cells via regulation of nuclear FoxO3A. Thorax 68: 131-141.

Germani A, Matrone A, Grossi V, Peserico A, Sanese P, Liuzzi M, Palermo R, Murzilli S, Campese AF, Ingravallo G, Canettieri G, Tezil T, Simone C (2014) Targeted therapy against chemoresistant colorectal cancers: Inhibition of $\mathrm{p} 38 \alpha$ modulates the effect of cisplatin in vitro and in vivo through the tumor suppressor FoxO3A. Cancer Lett 344: 110-118.

Gongora C, Candeil L, Vezzio N, Copois V, Denis V, Breil C, Molina F, Fraslon C, Conseiller E, Pau B, Martineau P, Del Rio M (2008) Altered expression of cell proliferation-related and interferon-stimulated genes in colon cancer cells resistant to SN38. Cancer Biol Ther 7: 822-832.

Grossi V, Liuzzi M, Murzilli S, Martelli N, Napoli A, Ingravallo G, Del Rio A, Simone C (2012) Sorafenib inhibits p38 $\alpha$ activity in colorectal cancer cells and synergizes with the DFG-in inhibitor SB202190 to increase apoptotic response. Cancer Biol Ther 13: 1471-1481.

Hegde PS, Rusnak D, Bertiaux M, Alligood K, Strum J, Gagnon R, Gilmer TM (2007) Delineation of molecular mechanisms of sensitivity to lapatinib in breast cancer cell lines using global gene expression profiles. Mol Cancer Ther 6: 1629-1640.

Ho K-K, McGuire VA, Koo C-Y, Muir KW, de Olano N, Maifoshie E, Kelly DJ, McGovern UB, Monteiro LJ, Gomes AR, Nebreda AR, Campbell DG, Arthur JS, Lam EW (2012) Phosphorylation of FOXO3a on Ser-7 by p38 promotes its nuclear localization in response to doxorubicin. J Biol Chem 287: 1545-1555.

Liu H-F, Hu H-C, Chao J-I (2010) Oxaliplatin down-regulates survivin by p38 MAP kinase and proteasome in human colon cancer cells. Chem Biol Interact 188: 535-545.

Lu Y, Liang K, Li X, Fan Z (2007a) Responses of cancer cells with wild-type or tyrosine kinase domain-mutated epidermal growth factor receptor (EGFR) to EGFR-targeted therapy are linked to downregulation of hypoxiainducible factor-1alpha. Mol Cancer 6: 63.

Lu Y, Li X, Liang K, Luwor R, Siddik ZH, Mills GB, Mendelsohn J, Fan Z (2007b) Epidermal growth factor receptor (EGFR) ubiquitination as a mechanism of acquired resistance escaping treatment by the anti-EGFR monoclonal antibody cetuximab. Cancer Res 67: 8240-8247.

Karapetis CS, Khambata-Ford S, Jonker DJ, O'Callaghan CJ, Tu D, Tebbutt NC, Simes RJ, Chalchal H, Shapiro JD, Robitaille S, Price TJ, Shepherd L, Au HJ, Langer C, Moore MJ, Zalcberg JR (2008) K-ras mutations and benefit from cetuximab in advanced colorectal cancer. N Engl J Med 359: $1757-1765$. 
Kawakami H, Okamoto I, Yonesaka K, Okamoto K, Shibata K, Shinkai Y, Sakamoto H, Kitano M, Tamura T, Nishio K, Nakagawa K (2014) The anti-HER3 antibody patritumab abrogates cetuximab resistance mediated by heregulin in colorectal cancer cells. Oncotarget 5: 11847-11856.

Khambata-Ford S, Garrett CR, Meropol NJ, Basik M, Harbison CT, Wu S, Wong TW, Huang X, Takimoto CH, Godwin AK, Tan BR, Krishnamurthi SS, Burris 3rd HA, Poplin EA, Hidalgo M, Baselga J, Clark EA, Mauro DJ (2007) Expression of epiregulin and amphiregulin and K-ras mutation status predict disease control in metastatic colorectal cancer patients treated with cetuximab. J Clin Oncol 25: 3230-3237.

Krol J, Francis RE, Albergaria A, Sunters A, Polychronis A, Coombes RC, Lam EW (2007) The transcription factor FOXO3a is a crucial cellular target of gefitinib (Iressa) in breast cancer cells. Mol Cancer Ther 6 : 3169-3179.

Marisa L, de Reyniès A, Duval A, Selves J, Gaub MP, Vescovo L, Etienne-Grimaldi MC, Schiappa R, Guenot D, Ayadi M, Kirzin S, Chazal M, Fléjou JF, Benchimol D, Berger A, Lagarde A, Pencreach E, Piard F, Elias D, Parc Y, Olschwang S, Milano G, Laurent-Puig P, Boige V (2013) Gene expression classification of colon cancer into molecular subtypes: characterization, validation, and prognostic value. PLoS Med 10: e1001453.

Montagut C, Dalmases A, Bellosillo B, Crespo M, Pairet S, Iglesias M, Salido M, Gallen M, Marsters S, Tsai SP, Minoche A, Seshagiri S, Serrano S, Himmelbauer H, Bellmunt J, Rovira A, Settleman J, Bosch F, Albanell J (2012) Identification of a mutation in the extracellular domain of the epidermal growth factor receptor conferring cetuximab resistance in colorectal cancer. Nat Med 18: 221-223.

Montagut C, Iglesias M, Arumi M, Bellosillo B, Gallen M, Martinez-Fernandez A, Martinez-Aviles L, Cañadas I, Dalmases A, Moragon E, Lema L, Serrano S, Rovira A, Rojo F, Bellmunt J, Albanell J (2010) Mitogen-activated protein kinase phosphatase-1 (MKP-1) impairs the response to anti-epidermal growth factor receptor (EGFR) antibody cetuximab in metastatic colorectal cancer patients. Br J Cancer 102: 1137-1144.

Okada Y, Miyamoto H, Goji T, Takayama T (2014) Biomarkers for predicting the efficacy of anti-epidermal growth factor receptor antibody in the treatment of colorectal cancer. Digestion 89: 18-23.

Paillas S, Boissière F, Bibeau F, Denouel A, Mollevi C, Causse A, Denis V, Vezzio-Vié N, Marzi L, Cortijo C, Ait-Arsa I, Askari N, Pourquier P, Martineau P, Del Rio M, Gongora C (2011) Targeting the p38 MAPK pathway inhibits irinotecan resistance in colon adenocarcinoma. Cancer Res 71: 1041-1049.

Paillas S, Causse A, Marzi L, de Medina P, Poirot M, Denis V, Vezzio-Vie N, Espert L, Arzouk H, Coquelle A, Martineau P, Del Rio M, Pattingre S, Gongora C (2012) MAPK14/p38 $\alpha$ confers irinotecan resistance to TP53defective cells by inducing survival autophagy. Autophagy 8: 1098-1112.

Real PJ, Benito A, Cuevas J, Berciano MT, de Juan A, Coffer P, Gomez-Roman J, Lafarga M, Lopez-Vega JM, Fernandez-Luna JL (2005) Blockade of epidermal growth factor receptors chemosensitizes breast cancer cells through up-regulation of Bnip3L. Cancer Res 65: 8151-8157.

Roepman P, Schlicker A, Tabernero J, Majewski I, Tian S, Moreno V, Snel MH, Chresta CM, Rosenberg R, Nitsche U, Macarulla T, Capella G, Salazar R, Orphanides G, Wessels LF, Bernards R, Simon IM (2014) Colorectal cancer intrinsic subtypes predict chemotherapy benefit, deficient mismatch repair and epithelial-to-mesenchymal transition. Int $J$ Cancer 134: 552-562.

Roy SK, Srivastava RK, Shankar S (2010) Inhibition of PI3K/AKT and MAPK/ ERK pathways causes activation of FOXO transcription factor, leading to cell cycle arrest and apoptosis in pancreatic cancer. J Mol Signal 5: 10.

Sadanandam A, Lyssiotis CA, Homicsko K, Collisson EA, Gibb WJ, Wullschleger S, Ostos LC, Lannon WA, Grotzinger C, Del Rio M, Lhermitte B, Olshen AB, Wiedenmann B, Cantley LC, Gray JW, Hanahan D (2013) A colorectal cancer classification system that associates cellular phenotype and responses to therapy. Nat Med 19: 619-625.

Schlicker A, Beran G, Chresta CM, McWalter G, Pritchard A, Weston S, Runswick S, Davenport S, Heathcote K, Castro DA, Orphanides G, French T, Wessels LF (2012) Subtypes of primary colorectal tumors correlate with response to targeted treatment in colorectal cell lines. $B M C$ Med Genomics 5: 66.

Siravegna G, Mussolin B, Buscarino M, Corti G, Cassingena A, Crisafulli G, Ponzetti A, Cremolini C, Amatu A, Lauricella C, Lamba S, Hobor S, Avallone A, Valtorta E, Rospo G, Medico E, Motta V, Antoniotti C, Tatangelo F, Bellosillo B, Veronese S, Budillon A, Montagut C, Racca P, Marsoni S, Falcone A, Corcoran RB, Di Nicolantonio F, Loupakis F, Siena S, Sartore-Bianchi A, Bardelli A (2015) Clonal evolution and resistance to EGFR blockade in the blood of colorectal cancer patients. Nat Med 21: 795-801.

Takeuchi K, Shin-ya T, Nishio K, Ito F (2009) Mitogen-activated protein kinase phosphatase-1 modulated JNK activation is critical for apoptosis induced by inhibitor of epidermal growth factor receptor-tyrosine kinase. FEBS J 276: 1255-1265.

Van Cutsem E, Nordlinger B, Cervantes A (2010) Advanced colorectal cancer: ESMO clinical practice guidelines for treatment. Ann Oncol 21(Suppl 5): v93-v97.

van der Vos KE, Coffer PJ (2011) The extending network of FOXO transcriptional target genes. Antioxid Redox Signal 14: 579-592.

Wilson KP, Fitzgibbon MJ, Caron PR, Griffith JP, Chen W, McCaffrey PG, Chambers SP, Su MS (1996) Crystal structure of p38 mitogen-activated protein kinase. J Biol Chem 271: 27696-27700.

Yang J-Y, Zong CS, Xia W, Yamaguchi H, Ding Q, Xie X, Lang JY, Lai CC, Chang CJ, Huang WC, Huang H, Kuo HP, Lee DF, Li LY, Lien HC, Cheng $\mathrm{X}$, Chang KJ, Hsiao CD, Tsai FJ, Tsai CH, Sahin AA, Muller WJ, Mills GB, Yu D, Hortobagyi GN, Hung MC (2008) ERK promotes tumorigenesis by inhibiting FOXO3a via MDM2-mediated degradation. Nat Cell Biol 10: 138-148.

Yang SY, Miah A, Sales KM, Fuller B, Seifalian AM, Winslet M (2011) Inhibition of the p38 MAPK pathway sensitises human colon cancer cells to 5-fluorouracil treatment. Int J Oncol 38: 1695-1702.

Zarubin T, Han J (2005) Activation and signaling of the p38 MAP kinase pathway. Cell Res 15: 11-18.

This work is published under the standard license to publish agreement. After 12 months the work will become freely available and the license terms will switch to a Creative Commons AttributionNonCommercial-Share Alike 4.0 Unported License.

Supplementary Information accompanies this paper on British Journal of Cancer website (http://www.nature.com/bjc) 